\section{Science in India}

The supplement on Indian science Nature 12 April (pp. 581-600) has prompted many reactions. Some are published here, with more next week.

SIR - The key to considering science and technology in India lies in recognizing that India is trying to go through three revolutions simultaneously - the agricultural (still incomplete), industrial and computer revolutions - with a government that is democratic, a population less than half of which is literate and resources that are hardly adequate for a task never before undertaken. This is the reason for the wide spectrum from poverty to excellence that one finds in India in all aspects of life. I do not think that Nature's supplement recognized this, explicitly at any rate.

A few careless statements crept in - for instance, "India... often describes itself as the third nation in the world of science and technology". The truth is that India does state frequently that it has the third largest scientific manpower, but mainly to illustrate that despite that fact, productivity is low in science, industry and everywhere.

But my main objection is to the way you depicted the central universities as "breeding grounds for violence", apparently on the basis of the report on the working of the central universities. The report has nothing to do with the actual work of the central universities and much less with science in them; rather it is concerned with factors preventing the central universities from working as they ought to. The report is in no way a guide to what the central universities are, any more than a pathologist's report reveals a man's personality.

In fact, the original concern of the report was precisely that of "finding some way to restore authority to where it belongs". For several decades, long before the Indian Institutes of Technology started to blaze their trails, the central universities, notably those of Delhi, Banaras and Aligarh, contributed much to science and humanities. It is totally wrong to say "nepotism, disorder (even violence) and maladministration are rife even in the seven (central) universities...", wherever this information came from.

Your sampling of the scientific institutions and scientists also appears to be inadequate. Unless one is careful, the visible and the vociferous have a high probability of looming large. But surprisingly, after all that is said, you have not given much, except, perhaps, a few more counts in the Science Citation Index. Yes, ambivalence seems to be a part of our relations.

But despite these complaints, and although I do not always agree with your conclusions, your survey is the most incisive analysis of the complex system of science in India. I agree with you that "India has by far the best chance of succeeding" in the development of science and technology, not because of "the ingenuity and articulateness of its people", but because, as Aldous Huxley pointed out (Science and Literature), one of the greatest achievements of science is to have developed a method independent of those who work with it.

\section{University of Hyderabad, Hyderabad 500 134, India}

SIR - You are, of course, right in saying that all is not well in India's Science. But great strides have been made. As our Prime Minister declared during a White House reception, India is engaged in the stupendous task of moving hundreds of millions of people into the twentieth century. Against this backdrop one can understand why our laboratories and classrooms are no longer sheltered. The attendant erosion of academic freedom, loss of objectivity and so on are inevitable, but, one expects, temporary phenomena.

Notwithstanding the problems, there have been some achievements (as noted by you also). The green revolution is a reality, and our chemical industry is able to lean on our own research and development. Where high technology is concerned, we can certainly claim we know how to launch a satellite and how to build a nuclear power station. On the more exotic basic research side, we cannot boast of a string of spectacular discoveries, but then our total investment relative to that in the West is paltry. If achievement is measured relative to obstacles overcome, our record measures up favourably to those of others.

All the same, we are neither satisfied nor complacent. Recently our two academies held a joint brainstorming session to examine how to improve matters. It was discovered (as expected) that streamlining Indian science was about as easy as holding a plasma at a million degrees in a container at laboratory temperature, and for essentially the same sort of reason. But some suggestions did emerge and they have been transmitted to the Science Advisory Committee to the Cabinet.

We are confident we will make it and are working hard towards that objective. As you remark, "the doubt is not whether but when". Meanwhile, our expatriate friends could note that Indian science cannot be bettered by simply asking "Is this all we have done . . .?" (Incidentally, what have those giving this advice done for us?) Nor will it be accomplished by listening to seminars by scientists coming for a family reunion or even under the auspices of an international committee.

Reactor Research Centre,

G. VENKATARAMAN

Kalpakkam 603 102, India
SIR - Readers of your survey are likely to conclude that most of what is good and worthy of its name in Indian science is so because (1) a director or a chairman or perhaps a minister knows and means his/her business; (2) they or their organizations have or at least had good overseas connections and (3) they have somehow managed to avoid the anything-butbeautiful influence of the run-of-the-mill scientific workers and of the people at large.

The major contradiction in Indian science is that of its patch excellence $v i s-d$ $v i s$ its unrootedness in Indian soil. Cooperation from scientifically advanced countries is necessary and should be welcomed. India neeeds to ensure a certain degree of immunity against the crisis, of which there are visible signs, by directing science in international directions. But the country also needs help in promoting the search for identity of the "two Indias".

With the general elections expected this year, the political undertone of the report carries significance. However "surprising" and "dangerous"' it may be for Indian science to be strongly influenced by the people in power, in fact its infective power seems to defy territorial confinement.

Lastly, for the sake of correctness of information, the Bose Institute of Calcutta is not and never was engaged in training graduates, nor is there any emphasis on nuclear physics in its research programmes. Neither of the two Boses received Nobel prizes, on which point there seems to be some misunderstanding (p.589-90).

Department of Ceramics,

R. MAJUMDAR

University of Leeds,

Leeds LS2 9JT, UK

SIR - Your special issue on India provides a comprehensive account of accomplishments, failures and problems of science in India. The introductory note to the survey, however, contains the erroneous figure of 2.5 per cent as the annual rate of India's current population growth. The registration of births and deaths in India is far from complete, but the annual population growth rate of 2.2 per cent during 1971-81, derived from the census counts of 1971 and 1981 , is considered by demographers as reasonably accurate. In a recent statement, Prime Minister Indira Gandhi gave the current annual growth rate as 1.9 per cent. The figure of 2.5 per cent instead of 1.9 per cent in the article does not, of course, affect its content or quality, but for India it means an increase of 19 million people every year instead of 14 million. Rapid population growth is a serious problem that Indian scientists and policymakers must tackle.

MONI NAG

The Population Council,

One Dag Hammarskjold Plaza,

New York,

New York 10017, USA 